\title{
Load sensing surgical instruments
}

\author{
C. Jacq, T. Maeder, P. Ryser \\ Laboratoire de Production Microtechnique, Ecole Polytechnique Fédérale de Lausanne \\ BM - Station 17, CH-1015 Lausanne, Switzerland \\ $+41.21 .693 .53 .85,+41.21 .693 .38 .91$, caroline.jacq@epfl.ch
}

\begin{abstract}
Force and pressure sensing technology applied to smart surgical instruments as well as implants allow to give a direct feedback of loads to the surgeon lead to better reliability and success of surgical operations. A common technology used for sensors is low-cost piezoresistive thick-film technology. However, the standard thick-film firing conditions degrade the properties of medical alloys.

In order to avoid this problem, the solution is to decrease the firing temperature of thick films. This work presents the development and characterisation of low-firing thickfilm systems (dielectrics, resistors and conductors), formulated to achieve chemical and thermal expansion compatibility with an austenitic stainless steel medical alloy. Adherence tests and results on electrical properties of these systems: resistance, temperature coefficient of resistance (TCR) are presented. It was found that the main issue in these systems lies in mastering the materials interactions during firing, especially at the silverbased resistor terminations. The interaction of silver, resistor and dielectric tends to give rise to highly resistive zones at the terminations, affecting reliability. This can be circumvented by post-firing the resistor terminations at a moderate temperature.
\end{abstract}

Key words: Thick-film materials, steel substrates, low-temperature processing, resistors, termination effects

\section{Introduction}

The overall object of this project is the application of force and pressure sensing technology to smart surgical instruments as well as implants. Smart instruments allowing direct feedback of loads to the surgeon lead to better reliability and success of surgical operations. Load-sensing implants are to be a useful tool in monitoring patient recovery in cases such as bone fracture, and also in aiding the re-education process.

A well established and low production cost solution for force and pressure sensing is thick-film piezoresistive technology, usually applied on ceramic substrates. However, alumina is not optimal for piezoresistive sensing applications, as it is brittle, its elastic modulus high and its strength rather low, compared to metallic materials such as highstrength stainless steels and $\mathrm{Ti}$ alloys [1][2], which are commonly applied for medical devices such as instruments, fixtures and implants.

Thick-film piezoresistive sensors on metallic substrates have been investigated previously [3], and used to fabricate a ligament balancing sensor for total knee arthroplasty (TKA) [4-6]. However, the standard thick-film firing temperature $\left(850^{\circ} \mathrm{C}\right)$ is not compatible with Ti alloys, which oxidise too extensively. Stainless steels, on the other hand, undergo degradation of mechanical properties due to annealing or phase transformations incompatible with the presence of thick-film layers.

Medical-grade austenitic stainless steels with nitrogen additions, such as the alloy used for the TKA sensor [4-6], do not undergo phase transformations, and nitrogen allows reasonable strength even in the annealed state. However, mechanical properties remain suboptimal, and these alloys have a very high coefficient of thermal expansion (CTE), ca. $17 \mathrm{ppm} / \mathrm{K}$ (vs. 11 for ferritic / martensitic steels and 7 for alumina). Therefore, standard thick-film materials tend to have poor reliability due to excessive stresses. That's why, a 
specific materials system, with a low firing temperature to conserve mechanical properties and with a CTE matched to that of the steel, is highly desirable.

In previous studies [7-10], we have developed and studied several such low-firing systems based on low-melting lead borosilicate glasses, where the materials were formulated to achieve compatibility with a wide range of substrates such as glass, aluminium metal and steels. CTE matching (which is important mainly for the insulating dielectric) was successfully achieved by adjusting the glass composition, the filler and the loading. One remaining problem was the presence of highly resistive zones near the resistor terminations, which is deleterious to reproducibility and reliability. This was mitigated on a system optimised for ferritic / martensitic stainless steels by post-firing the terminations at a low temperature and/or through $\mathrm{Bi}_{2} \mathrm{O}_{3}$ additions to the materials [11].

In this work, we therefore endeavour to systematically investigate the termination effect for our low-firing thick-film system adapted to austenitic steels (e.g. with a different formulation of the insulating dielectric), in the light of the previous study [11]. Additional integration issues such as adherence and conductor pad solderability are also studied.

\section{Experimental}

The following substrate materials were used: $96 \%$ pure alumina (Kyocera, Japan, A476) as standard thick-film substrate and austenitic stainless steel 1.4435 (comparable to the medical alloy used for the sensor). The steel substrates were pre-oxidised at $900^{\circ} \mathrm{C}$ during 1 hour in order to increase the adherence of the dielectrics.

All dielectric materials used in this work are based on the lead borosilicate glass ("V6") used in our previous studies [7-12]: $75 \% \mathrm{PbO}+10 \% \mathrm{~B}_{2} \mathrm{O}_{3}+15 \% \mathrm{SiO}_{2}$ (mass \%) with $2 \%$ $\mathrm{Al}_{2} \mathrm{O}_{3}$ added to inhibit crystallisation [13].

The basic dielectric sequence (variant "C") starts with a first layer with $25 \%$ vol. $\mathrm{Fe}_{2} \mathrm{O}_{3}$ as an adhesion promoter, followed by 2 layers filled with cristobalite (Quarzwerke, Sikron cristobalite flour SF8000 D50:2.5 $\mu \mathrm{m}$ particle size).

Two modifications to the top layer of this dielectric sequence, which is in contact with the resistor, were examined: 1) replacing the cristobalite filler with alumina $(\mathrm{C} \rightarrow \mathrm{A}$, Alfa Aesar, aluminium oxide alpha, 99.99\%, $1 \mu \mathrm{m}$ ), and/or 2) doping with $\mathrm{Bi}_{2} \mathrm{O}_{3}$ added as powder to the paste $\left(\mathrm{C}, \mathrm{A} \rightarrow \mathrm{C}_{\mathrm{Bi}}, \mathrm{A}_{\mathrm{Bi}}\right.$, Alpha Aesar 12230, 99\%). The volume fractions and codes of the resulting dielectrics are given in table 1. Together with the option of firing on bare alumina, this gives 5 dielectric + substrate variants. All the dielectric layers were fired separately at a peak temperature of $625^{\circ} \mathrm{C}$, with a $10 \mathrm{~min}$ dwell.

\begin{tabular}{|l|l|}
\hline Designation & $\begin{array}{l}\text { Description } \\
\text { (numbers in volume \%) }\end{array}$ \\
\hline \begin{tabular}{c|} 
Substrate + dielectrics: \\
$*$
\end{tabular} & (alumina substrate) \\
$\mathrm{C}$ & $40 \mathrm{~V} 6+60$ Cristobalite \\
$\mathrm{C}_{\mathrm{Bi}}$ & $32 \mathrm{~V} 6+58 \mathrm{Cristobalite}_{1} 10 \mathrm{Bi}_{2} \mathrm{O}_{3}$ \\
$\mathrm{~A}$ & $50 \mathrm{~V} 6+50 \mathrm{Al}_{2} \mathrm{O}_{3}$ \\
$\mathrm{~A}_{\mathrm{Bi}}$ & $40 \mathrm{~V} 6+50 \mathrm{Al}_{2} \mathrm{O}_{3}+10 \mathrm{Bi}_{2} \mathrm{O}_{3}$ \\
\hline Conductors \& order: & $100 \mathrm{ESL} 9912 \mathrm{~A}$ \\
$\mathrm{~V}$ & $85 \mathrm{ESL} 9912 \mathrm{~A}+15 \mathrm{Bi}_{2} \mathrm{O}_{3}$ \\
$\mathrm{~V}_{\mathrm{Bi}}$ & $90 \mathrm{Ag}+10 \mathrm{~V} 8$ \\
$\mathrm{~W}$ & $83 \mathrm{Ag}+7 \mathrm{~V} 8+10 \mathrm{Bi}_{2} \mathrm{O}_{3}$ \\
$\mathrm{~W}_{\mathrm{Bi}}$ & $100 \mathrm{ESL} \mathrm{3114}$ \\
\hline Resistors: & $90 \mathrm{ESL} 3114+10 \mathrm{Bi}_{2} \mathrm{O}_{3}$ \\
$\mathrm{R}_{\mathrm{Bi}}$ & \\
\hline
\end{tabular}

Table 1: List of materials

As pre-fired Ag conductors were found to give rise to undesirable high-resistivity zones near the terminations with our materials [11], we take in the present work the option 
of post-firing the terminations at a temperature lower than the one used for the resistor firing. A commercial $\mathrm{Ag}$ conductor material allowing a reduced firing temperature was applied: ESL $9912 \mathrm{~A}$, fired at $600^{\circ} \mathrm{C} / 10 \mathrm{~min}$. Additionally, the possibility of using a very low-firing $\left(500^{\circ} \mathrm{C}\right)$ conductor, consisting of $\mathrm{Ag}$ powder (Nanostrutured \& Amorphous Materials Inc. 99.9\%, APS $30 \mathrm{~nm}$ ) with a very low-melting glass binder ("V8", $85 \% \mathrm{PbO}+$ $10 \% \mathrm{~B}_{2} \mathrm{O}_{3}+5 \% \mathrm{SiO}_{2}$, mass $\%,+2 \% \mathrm{Al}_{2} \mathrm{O}_{3}$ [7-11]) was examined. As in the case of the dielectrics, doping with $\mathrm{Bi}_{2} \mathrm{O}_{3}$ was also examined. The resulting 4 conductors + firing order variants are given in tables 1 and 2 .

\begin{tabular}{|l|l|l|l|}
\hline $\begin{array}{l}\text { Dielectric } \\
625^{\circ} \mathrm{C}\end{array}$ & $\begin{array}{l}\text { Resistor } 625^{\circ} \mathrm{C} \\
\begin{array}{l}\text { Dielectric } \\
625^{\circ} \mathrm{C}\end{array}\end{array}$ & $\begin{array}{l}\text { Conductor } \\
500^{\circ} \mathrm{C}\end{array}$ & $\begin{array}{l}\text { Resistor \& } \\
\text { Conductor } \\
\text { reinforcement } \\
500^{\circ} \mathrm{C}\end{array}$ \\
$\begin{array}{l}625^{\circ} \mathrm{C} \\
\text { Conductor }\end{array}$ & $\begin{array}{l}\text { Conductor } \\
500^{\circ} \mathrm{C}\end{array}$ & \\
\hline
\end{tabular}

Table 2: Firing sequences

For the resistive composition, a commercial low-firing $10 \mathrm{kO}$ paste, ESL 3114, was used, also with or without $\mathrm{Bi}_{2} \mathrm{O}_{3}$ doping (table 1). In this study, the resistors were always fired at $625^{\circ} \mathrm{C} / 10 \mathrm{~min}$.

Two firing sequences, differing by the number of resistor firings, were also compared (table 2).

Samples for sheet resistance and TCR were $1.5 \mathrm{~mm}$ wide resistors of several lengths (figure 1), and were measured at $30^{\circ} \mathrm{C}, 65^{\circ} \mathrm{C}$ and $100^{\circ} \mathrm{C}$.

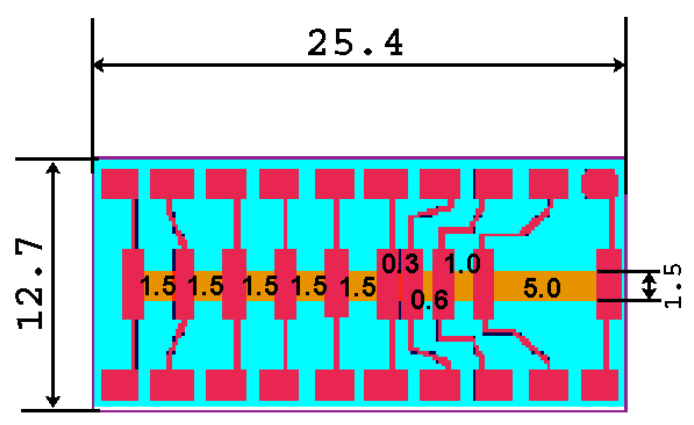

Fig 1: Layout of the test sample for measurement of electrical properties.

As in the previous study [11], termination effects were compared through a "length index" $\mathrm{LI}$, defined as the ratio of the average sheet resistance of the three short resistors $(0.3,0.6$ and $1.0 \mathrm{~mm}$ length) to the average of the $1.5 \mathrm{~mm}$ long ones. LI values greater than 1 imply the existence of highly resistive zones near the terminations, whereas the other case $(\mathrm{LI}<1)$ corresponds to a locally decreased sheet resistance near the terminations.

\section{Results and discussions}

The results for length index LI, sheet resistance $R_{s}$ and TCR are compiled in tables 3, 4 and 5 respectively. 


\begin{tabular}{|c|c|c|c|c|c|c|}
\hline $\begin{array}{c}\text { Cond. \& order } \\
\text { Sub.+ diel.+ res. }\end{array}$ & \multicolumn{7}{|c|}{ Resistor fired 3 times } & \multicolumn{2}{l|}{ Resistor fired 2 times } \\
\hline & $\mathbf{V}$ & $\mathbf{V}_{\mathbf{B i}}$ & $\mathbf{W}$ & $\mathbf{W}_{\mathbf{B i}}$ & $\mathbf{W}$ & $\mathbf{W}_{\mathbf{B i}}$ \\
\hline$*+\mathbf{R}$ & 1.41 & 1.47 & 0.87 & 0.90 & 0.95 & 0.91 \\
\hline$*+\mathbf{R}_{\mathbf{B i}}$ & 1.49 & 1.59 & 1.07 & 1.09 & 1.1 & 1.01 \\
\hline $\mathbf{C}+\mathbf{R}$ & 1.91 & 2.05 & 0.99 & 0.94 & 0.9 & 0.94 \\
\hline $\mathbf{C}+\mathbf{R}_{\mathbf{B i}}$ & 2.61 & 2.54 & 1.06 & 1.08 & 1.01 & 0.99 \\
\hline $\mathbf{C}_{\mathbf{B i}}+\mathbf{R}$ & 2.27 & 2.12 & 0.94 & 0.91 & 0.97 & 0.94 \\
\hline $\mathbf{C}_{\mathbf{B i}}+\mathbf{R}_{\mathbf{B i}}$ & 2.22 & 2.42 & 1.02 & 1.12 & 1.10 & 1.02 \\
\hline $\mathbf{A}+\mathbf{R}$ & 3.44 & 2.62 & 1.00 & 1.03 & 1.01 & 0.99 \\
\hline $\mathbf{A}+\mathbf{R}_{\mathbf{B i}}$ & 2.99 & 3.17 & 1.09 & 1.10 & 1.09 & 1.05 \\
\hline $\mathbf{A}_{\mathbf{B i}}+\mathbf{R}$ & 2.31 & 3.12 & 1.07 & 1.07 & 0.98 & 0.96 \\
\hline $\mathbf{A}_{\mathbf{B i}}+\mathbf{R}_{\mathbf{B i}}$ & 3.09 & 2.77 & 1.23 & 1.16 & 1.12 & 1.14 \\
\hline
\end{tabular}

Table 3: Length index LI

\begin{tabular}{|c|c|c|c|c|c|c|}
\hline \multirow{2}{*}{$\begin{array}{c}\text { Cond. \& order } \\
\text { Sub. diel. + res. }\end{array}$} & \multicolumn{9}{|c|}{ Resistor fired 3 times } & \multicolumn{2}{c|}{ Resistor fired 2 times } \\
\cline { 2 - 7 } & $\mathbf{V}$ & $\mathbf{V}_{\mathbf{B i}}$ & $\mathbf{W}$ & $\mathbf{W}_{\mathbf{B i}}$ & $\mathbf{W}$ & $\mathbf{W}_{\mathbf{B i}}$ \\
\hline$*+\mathbf{R}$ & 16.68 & 22.3 & 12.4 & 12.39 & 10.62 & 9.97 \\
\hline$*+\mathbf{R}_{\mathbf{B i}}$ & 5.68 & 5.29 & 3.82 & 3.80 & 3.31 & 3.46 \\
\hline $\mathbf{C}+\mathbf{R}$ & 32.35 & 33.25 & 13.79 & 13.85 & 11.68 & 11.6 \\
\hline $\mathbf{C}+\mathbf{R}_{\mathbf{B i}}$ & 22.36 & 20.55 & 8.31 & 7.54 & 7.3 & 6.58 \\
\hline $\mathbf{C}_{\mathbf{B i}}+\mathbf{R}$ & 21.53 & 18.74 & 8.1 & 8.24 & 6.88 & 6.96 \\
\hline $\mathbf{C}_{\mathbf{B i}}+\mathbf{R}_{\mathbf{B i}}$ & 28.48 & 23.28 & 6.43 & 6.8 & 6.5 & 5.66 \\
\hline $\mathbf{A}+\mathbf{R}$ & 41.78 & 33.55 & 7.51 & 7.96 & 6.52 & 6.84 \\
\hline $\mathbf{A}+\mathbf{R}_{\mathbf{B i}}$ & 21.37 & 15.78 & 4.01 & 3.97 & 3.85 & 3.90 \\
\hline $\mathbf{A}_{\mathbf{B i}}+\mathbf{R}$ & 19.19 & 16.34 & 4.39 & 4.36 & 3.93 & 4.1 \\
\hline $\mathbf{A}_{\mathbf{B i}}+\mathbf{R}_{\mathbf{B i}}$ & 14.79 & 12.17 & 3.51 & 3.41 & 3.07 & 2.99 \\
\hline
\end{tabular}

Table 4: Sheet resistance Rs [kO] 


\begin{tabular}{|c|c|c|c|c|c|c|}
\hline $\begin{array}{c}\text { Cond. \& order } \\
\text { Sub.+ diel. + res. }\end{array}$ & \multicolumn{7}{|c|}{ Resistor fired 3 times } & \multicolumn{2}{c|}{ Resistor fired 2 times } \\
\hline & $\mathbf{V}$ & $\mathbf{V}_{\mathbf{B i}}$ & $\mathbf{W}$ & $\mathbf{W}_{\mathbf{B i}}$ & $\mathbf{W}$ & $\mathbf{W}_{\mathbf{B i}}$ \\
\hline & & & & & -274 & -263 \\
\hline$*+\mathbf{R}$ & -285 & -286 & -263 & -292 & -274 & -274 \\
\hline$*^{+} \mathbf{R}_{\mathbf{B i}}$ & -273 & -269 & -267 & -264 & -274 \\
\hline $\mathbf{C}+\mathbf{R}$ & 49 & 71 & -46 & -72 & -52 & -57 \\
\hline $\mathbf{C}+\mathbf{R}_{\mathbf{B i}}$ & -119 & -113 & -135 & -139 & -127 & -125 \\
\hline $\mathbf{C}_{\mathbf{B i}}+\mathbf{R}$ & -15 & -5 & -74 & -83 & -65 & -70 \\
\hline $\mathbf{C}_{\mathbf{B i}}+\mathbf{R}_{\mathbf{B i}}$ & -120 & -134 & -136 & -123 & -126 & -130 \\
\hline $\mathbf{A}+\mathbf{R}$ & 97 & 102 & 36 & 23 & 48 & 38 \\
\hline $\mathbf{A}+\mathbf{R}_{\mathbf{B i}}$ & -10 & -2 & -31 & -35 & -31 & -24 \\
\hline $\mathbf{A}_{\mathbf{B i}}+\mathbf{R}$ & 17 & 31 & 5 & 0 & 10 & 9 \\
\hline $\mathbf{A}_{\mathbf{B i}}+\mathbf{R}_{\mathbf{B i}}$ & -15 & -8 & -4 & -7 & 2 & 5 \\
\hline
\end{tabular}

Table 5: Temperature coefficient TCR $[\mathrm{ppm} / \mathrm{K}]$

The most important factor is the firing temperature of the terminations. ESL 9912A (variants $\mathrm{V} \& \mathrm{~V}_{\mathrm{Bi}}$ ), doped or not with $\mathrm{Bi}_{2} \mathrm{O}_{3}$ fired at $600^{\circ} \mathrm{C}$, is not suitable for the terminations, as LI is very high for all variants with this conductor. On the other hand, the low-firing $\left(500^{\circ} \mathrm{C}\right)$ terminations $\left(\mathrm{W} \& \mathrm{~W}_{\mathrm{Bi}}\right)$ minimise interdiffusion and exhibit LI values close to 1 , indicating much smaller termination effects. Also, TCR values also exhibit little influence of length. We will therefore concentrate the rest of the discussion on these samples.

The number of firings of the resistors $\left(2\right.$ or 3 , with 1 or 2 refires at $500^{\circ} \mathrm{C}$ ) has some influence: while TCR and LI are little affected, a second refire increases resistance around $15 \%$.

Doping the resistors and the dielectric with $\mathrm{Bi}_{2} \mathrm{O}_{3}$ strongly decreases both sheet resistance and TCR on steel, and only sheet resistance on alumina. $\mathrm{Bi}_{2} \mathrm{O}_{3}$ in the dielectric has a smaller effect, and probably acts through diffusion of this oxide into the resistor (this is supported by the fact that the effect on $\mathrm{Bi}_{2} \mathrm{O}_{3}$-doped resistors is much smaller). This decrease of resistivity occurs in spite of the corresponding dilution effect. Therefore, $\mathrm{Bi}_{2} \mathrm{O}_{3}$ clearly interacts with the resistor material and lowers its resistivity, probably by dissolving into the lead borosilicate glass matrix, which has an effect analogous to an increase of $\mathrm{PbO}$ in the glass $[13,14]$. On the other hand, adding $\mathrm{Bi}_{2} \mathrm{O}_{3}$ to the conductor has nearly no influence on the electrical properties ( $\mathrm{W}$ vs. $\mathrm{W}_{\mathrm{Bi}}$ ), except a slight decrease of TCR when Bi is absent from both dielectric and resistor.

The type of filler in the dielectric also has a significant effect: resistance is lower and TCR more positive with alumina than with cristobalite filler. This is ascribed to differences of chemical reactivity: alumina is very inert, whereas cristobalite, a form of $\mathrm{SiO}_{2}$, will tend to dissolve partially into the resistor glass.

Overall, if one considers $\mathrm{Bi}_{2} \mathrm{O}_{3}$ to be analogous to $\mathrm{PbO}$, our observations are in line with that of Adachi and Kuno [16], who found that resistivity is high with low-lead (high $\mathrm{SiO}_{2}$ ) glasses, and low with high-lead ones.

Figure 2 illustrates the dependence of sheet resistance with the length of resistance. Size effects have been completely circumvented by using the low temperature fired conductor. 


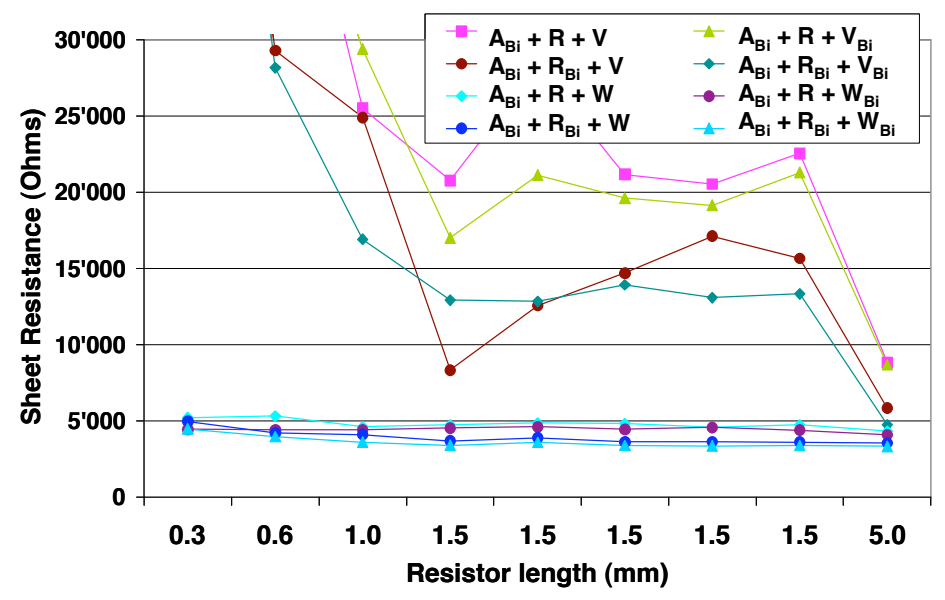

Fig 2: Evolution of sheet resistance with length of resistors.

Pull tests have been used to evaluate the adherence and the solderability of the thickfilm conductors. Both conductors $\mathrm{V}$ and $\mathrm{W}$ have been tested with SN96 solder $(96.5 \% \mathrm{Sn}$ $3.5 \% \mathrm{Ag}$ ). The force at rupture has been measured on the four dielectrics and alumina substrate as reference. The results are depicted on the figure 3 .

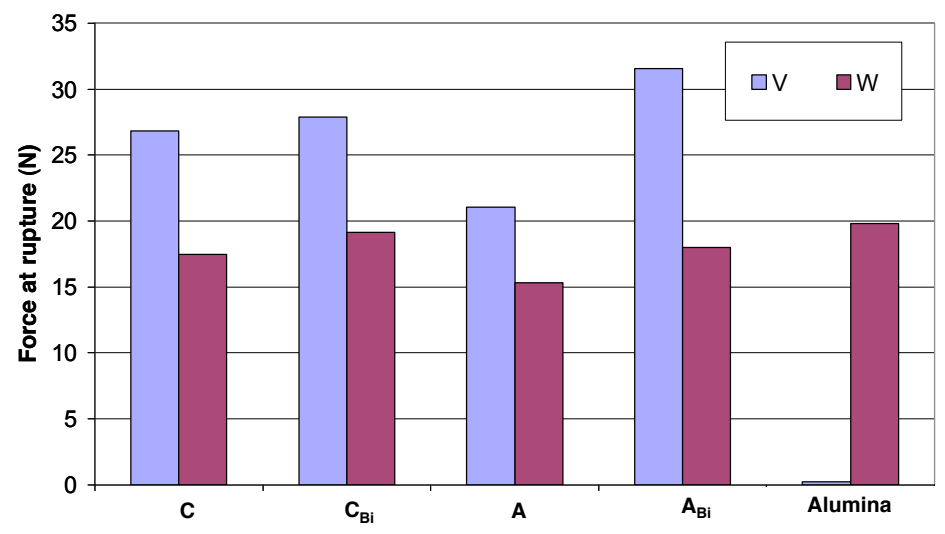

Figure 3: Adherence test on 1.4435 steel

The V conductor (ESL 9912A) could not be tested on alumina substrate because this conductor requires $850^{\circ} \mathrm{C}$ to adhere to this substrate. On the other hand, this conductor gives the best adhesion strength on dielectric, which is due to better wettability of the solder, which is facilitated by the low glass content of this conductor. During the pull test, fracture occurs both in the dielectric and the conductor. Therefore, the most favourable solution for applications is to co-fire ESL 9912A solder pads with the resistor, and then apply (post-fire) low-firing Ag for the resistor terminations.

The $\mathrm{Fe}_{2} \mathrm{O}_{3}$ was found to be an efficient adhesion promoter for dielectric on steel; failure nearly never occurs at the metal - dielectric interface, but mostly in the dielectric or at the conductor / dielectric interface. The beneficial effects of $\mathrm{Fe}_{2} \mathrm{O}_{3}$ are thought to be due to it preventing the occurrence of reducing conditions at the metal-dielectric interface through a redox mechanism. Similar results may be obtained with oxides of $\mathrm{Ni}, \mathrm{Cu}, \mathrm{Mn}$, Co, etc. 


\section{Conclusions and outlook}

The goal of this work was to study low-firing thick-film materials for piezoresistive sensor applications on medical-grade austenitic stainless steels, and achieve a reliable system.

Previously occurring issues with highly resistive zones near the silver terminations have been solved by developing conductors post-fireable at a low temperature $\left(500^{\circ} \mathrm{C}\right)$, although stability of this solution must be studied in the future.

Dielectrics filled with cristobalite were used to match the CTE of the substrate, but were found to somewhat interact with the resistors. In order to reduce this effect, a top layer filled with alumina was added as a diffusion barrier.

Doping the dielectric and/or the resistive material (ESL 3114) with $\mathrm{Bi}_{2} \mathrm{O}_{3}$ was found to strongly reduce the resistivity. The effect on the piezoresistive properties must still be elucidated.

For a good solderability and adherence, the conductor ESL 9912A fired with the resistors is the best conductor for a solder connection, and the $\mathrm{Fe}_{2} \mathrm{O}_{3}$ filler guaranteed good adhesion of the dielectric to the steel.

Although the sensors are coated with parylene to render them biocompatible[6], the presence of lead-based materials within medical sensors, even in a relatively insoluble glass matrix, is a cause of concern. Therefore, future work will focus on the elimination of lead from the glass matrix used in this thick-film system.

\section{References}

[1] C. JACQ, T. MAEDER, P. RYSER, "High-strain response of piezoresistive thick-film resistors on titanium alloy substrates", Journal of the European Ceramic Society, Vol. 24, No. 6, pp. 1897-1900, 2004.

[2] T. MAEDER, H. BIROL, C. JACQ, P. RYSER, "Strength of ceramic substrates for piezoresistive thick-film sensor applications", Proceedings, European Microelectronics and Packaging Symposium, Prague (CZ), pp.272-276, 2004.

[3] N.M. WHITE, "A study of the piezoresistive effect in thick-film resistors and its application to load transduction", thesis, University of Southampton, Faculty of Engineering \& Applied Science, 1988.

[4] D. CROTTET, T. MAEDER, D. FRITSCHY, H. BLEULER, LP NOLTE and IP. PAPPAS, "Development of a force amplitude- and location-sensing device designed to improve the ligament balancing procedure in TKA", IEEE Transactions on Biomedical Engineering, Vol. 52 (9), 1609-1611, 2005.

[5] D. CROTTET, J. KOWAL, SA. SARFERT, T. MAEDER, H. BLEULER, LP. NOLTE ad L. DÜRSELEN, "Ligament balancing in TKA: Evaluation of a force-sensing device and the influence of patellar eversion and ligament release", Journal of Biomechanics, Vol. 40 (8), 1709-1705, 2007.

[6] D. CROTTET, T. MAEDER, SA. SARFERT, D. FRITSCHY, H. BLEULER, LP. NOLTE and IP. PAPPAS, "In-vitro evaluation of a force-sensing device for ligament balancing in TKA", 51st Annual Meeting of the Meeting of the Orthopaedic Research Society, Washington (USA), 2005.

[7] C. JACQ, T. MAEDER, S. MARTINERIE, G. CORRADINI, E. CARREÑOMORELLI, P. RYSER, "High performance thick-film pressure sensors on steel", Proceedings, 4th European Microelectronics and Packaging Symposium, Terme Catež (SI), IMAPS, pp. 105-109, 2006.

[8] C. JACQ， S. VIONNET, T. MAEDER，P. RYSER，"Integrated thick-film hybrid microelectronics on aluminium substrates", Proceedings, European Microelectronics and Packaging Symposium, Prague (CZ), pp. 267-271, 2004.

[9] C. JACQ, T. MAEDER, S. VIONNET, P. RYSER, "Low-temperature thick-film dielectrics and resistors for metal substrates", Journal of the European Ceramic Society, Vol. 25 (12), pp. 2121-2124, 2005.

[10] C. JACQ, T. MAEDER, S. MENOT-VIONNET, H. BIROL, I. SAGLINI, P. RYSER, "Integrated thick-film hybrid microelectronics applied on different material substrates", Proceedings of the 15th European Microelectronics and Packaging Conference (EMPC), Brugge (BE), IMAPS, pp. S13.04, 319-324, 2005. 
[11]C. JACQ, T. MAEDER, N. JOHNER, G. CORRADINI, P. RYSER, "High performance low-firing temperature thick-film pressure sensors on steel", Proceedings of the $16^{\text {th }}$ European Microelectronics and Packaging Conference (EMPC), Oulu (FI), IMAPS, pp. 167-170.

[12] S. VIONNET-MENOT, C. GRIMALDI, T. MAEDER, P. RYSER, S. STRÄSSLER, "Tunneling-percolation origin of nonuniversality: Theory and experiments", Physical Review B, Vol. 71, pp. 064201, 2005.

[13] M. PRUDENTIATI, B. MORTEN, B. FORTI, A.F. GUALTIERI, G.M. DILLIWAY, "Devitrification kinetics of high lead glass for hybrid microelectronics", International Journal of Inorganic Materials, Vol. 3, pp. 667-674, 2001.

[14] M. HAMEZAN, HAA. SIDEK, AW. ZAIDAN, K. KAIDA, AT. ZAINAL, "Elastic constants and thermal properties of lead-bismuth borate glasses", Journal of Applied Sciences, Vol. 6 (4), 943-949, 2006.

[15]GE. RACHKOVSKAYA, GB. ZAKHAREVICH, "Properties, structure, and application of low-melting lead-bismuth glasses", Glass and Ceramics, Vol. 61 (1-2), 9-12, 2004.

[16] K. ADACHI, H. KUNO, "Effect of glass composition on the electrical properties of thick-film resistors", Journal of the American Ceramic Society, Vol. 83 (10), 2441$2448,2000$. 